\title{
Alternative System of Industrial Paint Applied to Spherical Mount for Liquefied Petroleum Gas
}

\author{
Fernando B. Mainier ${ }^{1}$, Francisco Otavio Pereira da Silva², Gilberto Oliveira da Silva ${ }^{2}$ \\ ${ }^{1}$ Escola de Engenharia, Universidade Federal Fluminense (UFF), Niterói, Brazil \\ ${ }^{2}$ Petrobras-Petróleo Brasileiro SA, Rio De Janeiro, Brazil \\ Email: fmainier@uol.com.br, fotavio@petrobras.com.br, gos@uol.com.br
}

Received 15 April 2014; revised 2 May 2014; accepted 16 May 2014

Copyright @ 2014 by authors and Scientific Research Publishing Inc.

This work is licensed under the Creative Commons Attribution International License (CC BY). http://creativecommons.org/licenses/by/4.0/

c) (†) Open Access

\begin{abstract}
The present article reports the application of zinc ethyl silicate paint and the use of internal and external paint schemes on carbon steel spheres for the storage of liquefied petroleum gas. The new paint scheme eliminates the steps of blasting in the field and minimizes the collection of waste generated and the environmental impact, reducing the service time onsite and therefore providing a productivity gain and better health and cleanliness at work. The results were obtained through test runs and qualified in bodies-of-proof made with the same characteristics as the sphere, that is, using the same material (carbon steel), thickness, and mechanical formation and subject to the same conditions of design and implementation process. The paint scheme was approved, qualified, and committed to the supplier's warranty with the paint manufacturer and assembler of the storage spheres for liquefied petroleum gas.
\end{abstract}

\section{Keywords}

Paint, Corrosion, Zinc Ethyl Silicate, Liquefied Petroleum Gas, Carbon Steel Spheres

\section{Introduction}

Carbon steel has been the most widely used material in most segments of basic production assets of the society. And, in recent decades, there has been considerable progress in both the manufacture of new alloys and nonferrous alloys and the development of new composite materials. However, given the scope of the use of common carbon steel, it is expected that the field of exposure to deterioration also occurs widely. In the case of petroleum refineries and petrochemical plants, the study of the corrosion processes has a bigger place, when one takes into 
account that about $50 \%$ of the failures of materials are credited to corrosion. The process of applying knowledge to corrosion principles and anti-corrosion protection as well as rules about practical suitability has been a challenge in the field of engineering equipment [1] [2].

Carbon steel is the main material used in the manufacture of equipment and industrial pipes; however due to corrosion the possibility of industrial use is dependent on the use of anti-corrosion coatings, and industrial painting stands out among the anti-corrosion processes. Protective coatings are generally applied on metallic surfaces to form a barrier between the surface and the corrosive medium and therefore prevent or minimize the corrosion process [3] [4].

The coatings can be metallic, organic, inorganic, or composite and their use for corrosion prevention will depend on a number of factors such as the nature of the corrosive medium, temperature, pressure, material hardness, mechanical strength, thermal conductivity, electrical conductivity, cost, and so on.

Industrial painting can be defined as any composition of chemicals, both organic and inorganic, applied as a liquid or paste to form a film on the surfaces of materials, which will undergo subsequent hardening, forming a solid adherent coating that is able to protect the materials against various corrosive media. The thicknesses of the coatings on metallic surfaces can vary from 60 to $500 \mu \mathrm{m}$, depending on the use and the aggressiveness of corrosive media [5].

Industrial painting of field industrial equipment can be carried out by applying industrial coatings using mobile facilities that comprise abrasive blasting machines, manual or automatic spray guns, and other equipment necessary for the application of paints.

Industrial painting must be based on the principles of quality and premises related to standards, procedures, occupational health, industrial safety, and the environment. Therefore, industrial painting must be suited to the organizational process under which all steps of the processes adopted are planned, implemented, monitored, recorded, reported, and archived.

It is important to note that even with paint application standards, periodic inspection is essential in the monitoring of their performance against the corrosive medium conditions and estimated life cycle. On-the-spot inspection aims to assess the failures by corrosion as well as mechanical damage generated by the transport and other operations. The inspection must be carried out to the full extent of the application; however, special attention should be given to sharp corners, welded areas, cracks, edges, and so on. This article aims to show the advantages of painting metallic parts at the plant and apply the final welding on the field.

\section{Manufacture and Assembly of the Spheres Considering the Use of the Conventional Scheme Paint and the Shop Primer Scheme Paint}

The painting of spheres for storage of liquefied petroleum gases is usually carried out on the construction site. The lining of this equipment is based on the operating conditions, environmental conditions, and costs, and its scope includes the treatment of surfaces, the paint, and its application.

Petrobras Standard N-1375 [6] defines the paint schemes of the liquefied gas storage spheres as environmental and operational conditions. In the case of base paint (shop primer), liquid paint (ethyl silicate inorganic zinc) is used on the basis of the Petrobras Standard N-1841 [7].

This paint has a high content of metallic zinc in the dry film of zinc-rich coatings (minimum $85 \% \mathrm{Zn}$ by weight), which provides a greater weather resistance; however, it interferes directly in the operation of oxy-cutting (cutting of sheets and pipes using a blowtorch with oxidizing gas mixtures) and welding of the plates. In the process of oxy-cutting, torch nozzle clogging can occur, while at low speeds the formation of pores can take place, forcing the removal of welded joints.

In addition, due to the high temperatures of these processes the formation of toxic fumes (zinc in gaseous form) occurs, damaging the health of workers involved directly with the welding process. Classification societies are non-governmental organizations that establish and maintain technical standards for the construction and operation of ships, offshore structures, petroleum refineries, and so on. These classification societies do not certify this paint for use in welding operations, and therefore there can be a risk to the health of workers.

The proposed process uses a modified paint formulation with low zinc content which has excellent anti-corrosion properties and is compatible with oxy-cutting processes and automatic welding [8]. Due to the low formation of toxic fumes (determined by laboratory analysis), international classifications societies have awarded the welding certificate. 


\subsection{Conventional Scheme without Application of Painting "Shop Primer"}

In the conventional system, the storage spheres of liquefied petroleum gas are assembled from modules of carbon steel sheets without application of the paint system, as shown in Figure 1 and Figure 2.

After industrial assembly of the modules, heat-treatment of weld beads is carried out and then the entire sphere is blasted with steel shot. Subsequently, the base paint (shop primer) and then finally the finishing paint are applied.

\subsection{Proposed Scheme of Assembly with the Application Modules Painted with Ethyl Zinc Silicate Paint (Modified Shop Primer)}

The new proposed process consists, essentially, of two phases. In the first phase, the carbon steel modules are blasted with steel shot; then they are painted at the factory (Figure 3) and transported for the assembly into a sphere in the field (Figure 4).

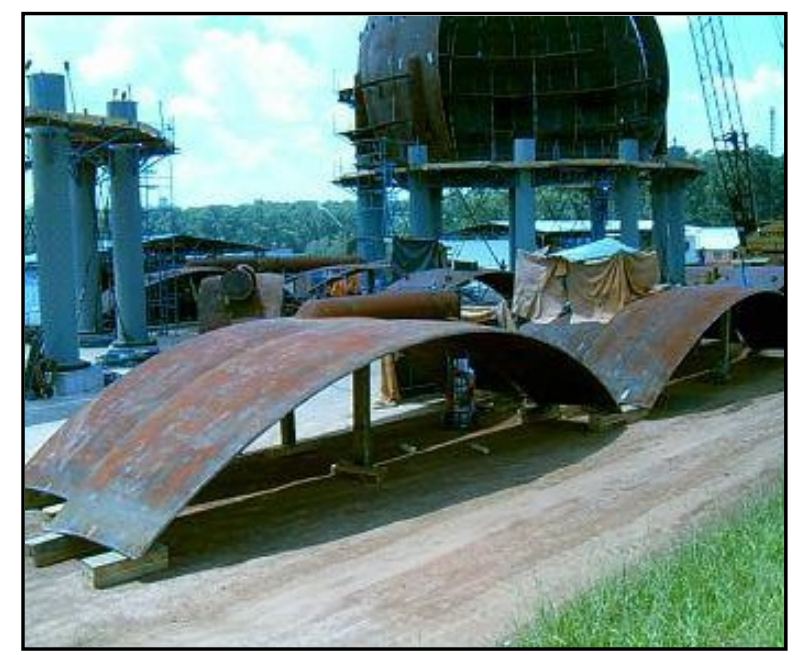

Figure 1. Industrial assembly of the sphere modules without paint application.

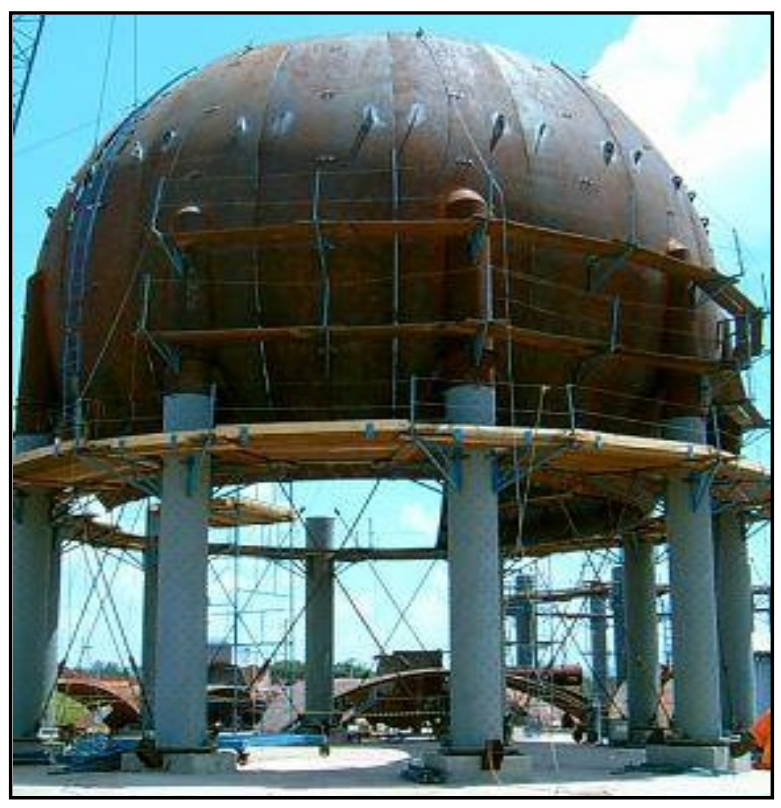

Figure 2. Sphere modules without paint application. 


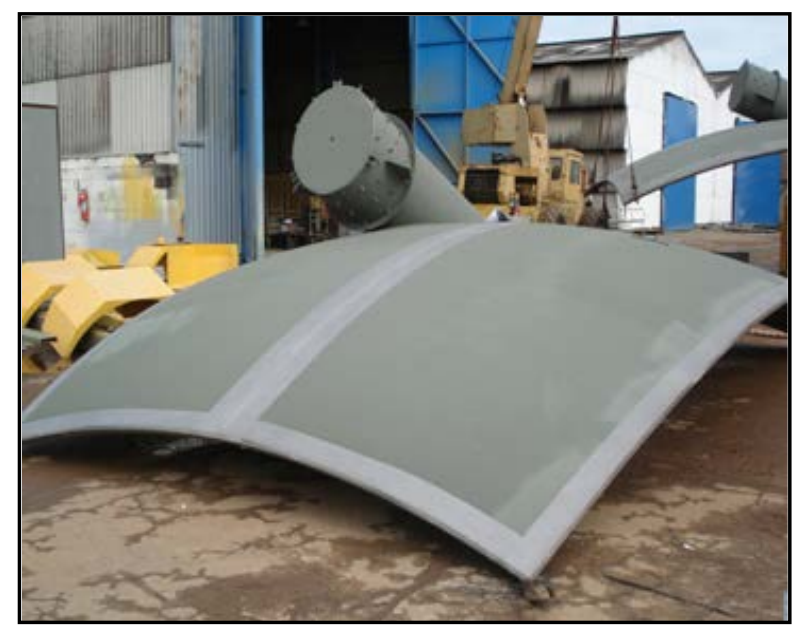

Figure 3. Painting of the module at the factory.

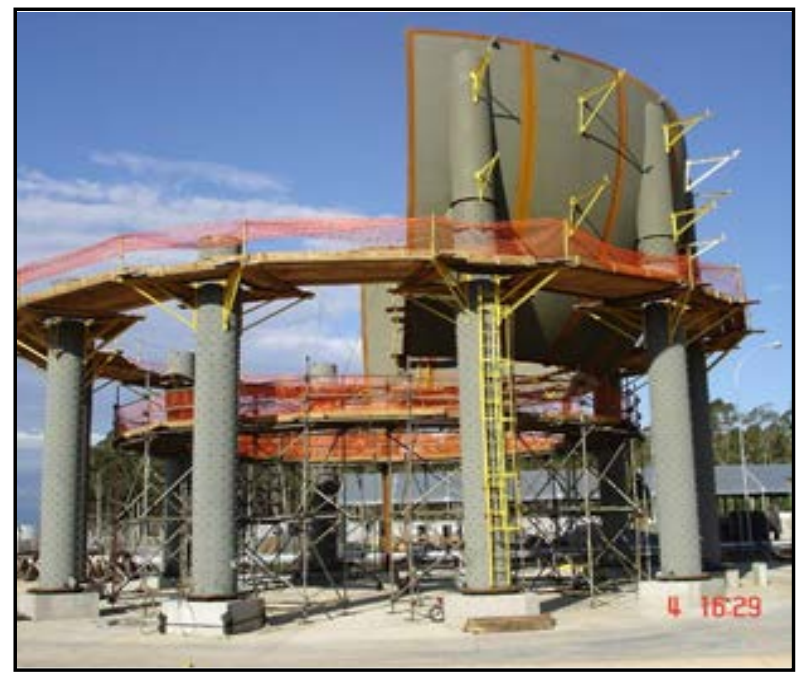

Figure 4. Assembly of the ready-painted module on the field.

The second phase in the field, the assembly sequence, consists of the following steps: welding of modules, heat treatment in weld beads, painting of weld beads, hydro blasting with low-pressure water over the applied paint, and finally finish painting (Figure 5 and Figure 6).

\section{Qualification of the Spheres Assembly Procedures Using Proof-Bodies Painted with Zinc Silicate Ethyl Modified Paint}

The methodology of qualification procedures for painting of sphere assembly modules at the factory essentially consists of the preparation of bodies-of-proof (BPs) with the same carbon steel and same thicknesses following the same procedures as were carried out in the assembly of the sphere in the field. Such processes are based on Procedure CQEQ-064 Petrobras (Qualification of Procedure of Storage Sphere Painting of Liquefied Petroleum Products [9].

The BPs used in the experiments was removed from a surplus (unused) part of the sphere assembly after the conformation process and cut by oxy-fuel cutting into a sample with dimensions of $1400 \times 800 \times 50 \mathrm{~mm}$, as shown in Figure 7. Then, the BP was blasted with steel shot based on Standard ISO 8501 [10], thus forming a roughness profile in the range of 40 to $70 \mu \mathrm{m}$.

In the preparation of $\mathrm{BP}$ it is essential to evaluate the local environmental conditions (relative humidity, temperature, dew point, and temperature of carbon steel sheet) prior to application of the paint, using as reference 


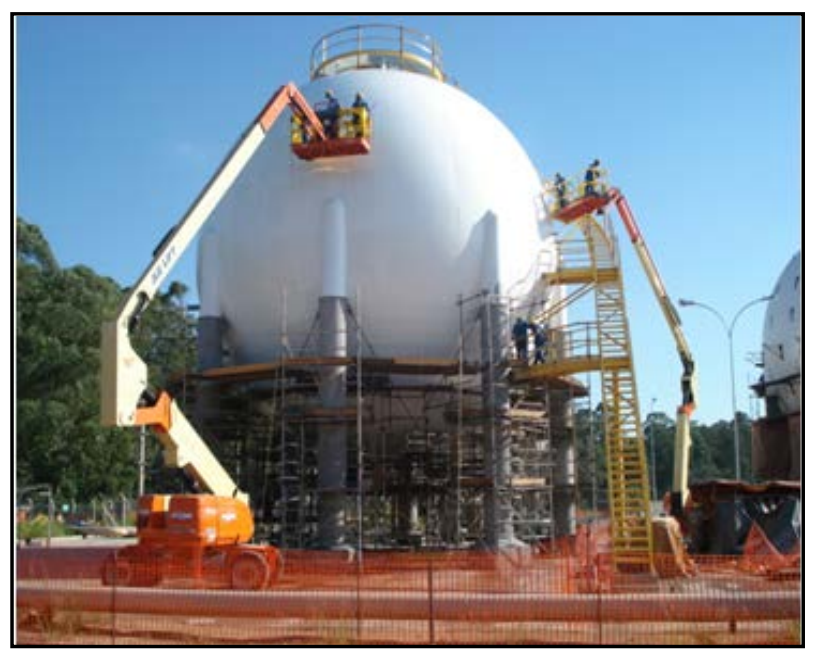

Figure 5. Application of finishing paint.

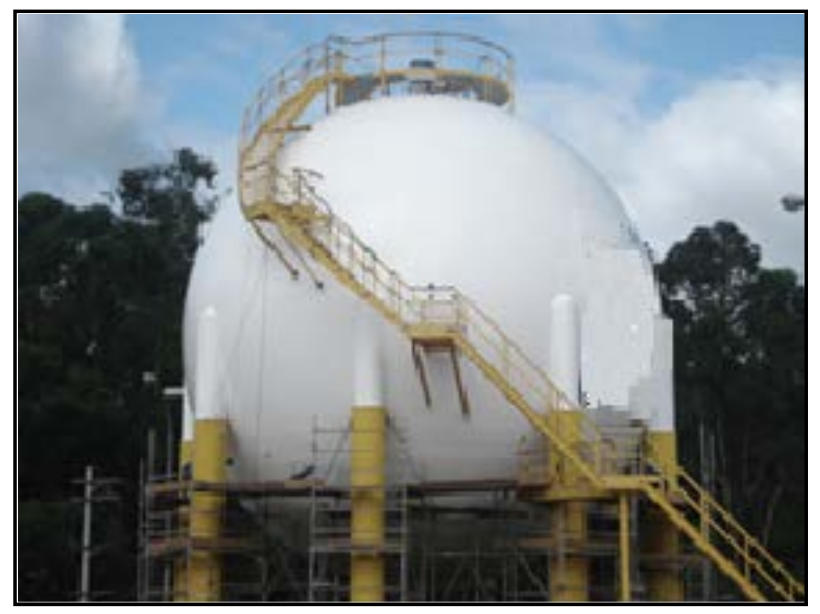

Figure 6. Final finished painted sphere.

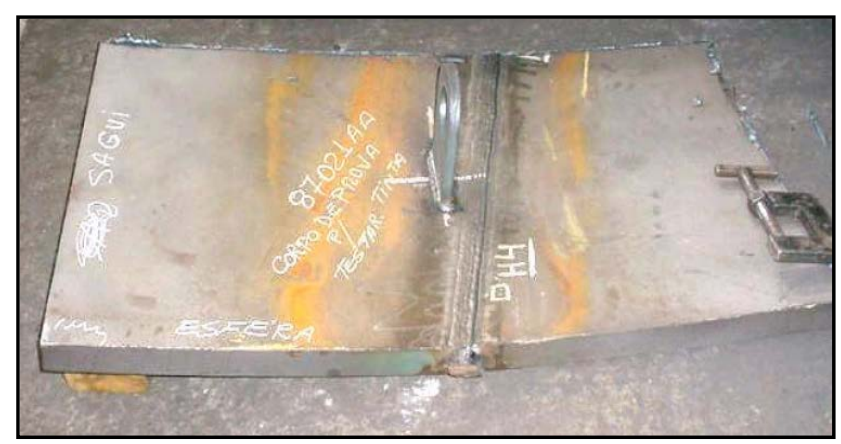

Figure 7. The body-of-proof (BP) used in the experiments (qualification).

the Petrobras Standard N-0013 [11].

After surface preparation, one 25-to-30- $\mu$ m coat of ethyl silicate zinc modified paint (shop primer paint) was applied using a spray gun with a tank mechanical stirrer and spray pressure of 40 psi (Figure 8).

Back to reinforce the procedures adopted in the body-of-proof (BP) are identical to those adopted for the sphere assembly. 
Besides the field and assembly simulation of all procedures performed on the sphere, the body-of-proof (BP) was cut in half, bevelled, and welded with the same characteristics as those used on the sphere project construction site.

To further verify the behaviour of paint in real assembly conditions, the painted BP was submitted to heat treatment (Figure 9) in the same conditions of heat treatment as for the sphere assembly.

One of the most important points in this work is to qualitatively and quantitatively verify the paint behaviour considering that the soldering temperature and subsequent heat treatment can reach temperatures of $650^{\circ} \mathrm{C}$. The biggest expectation would know how "shop primer paint" would behave after heat treatment, reaching temperatures of approximately $650^{\circ} \mathrm{C}$. However, one of the features of this paint is the ability to withstand high temperatures.

As shown in Figure 10, after removal from heat treatment, the body-of-proof (BP) presented dark spots; however, adhesion tests carried out on the basis of the standards ABNT NBR 11003 [12] and Petrobras N-0013 [13] showed good results.

Painting procedures after heat treatment and application of one coat of epoxy-zinc phosphate paint as the base consisted of the following steps. The first was cleaning of the surface of the BP by hydro blasting with fresh water (pH between 6.5 and 7.5) at a pressure of 3000 to 4000 psi. After full drying one coat of epoxy-zinc

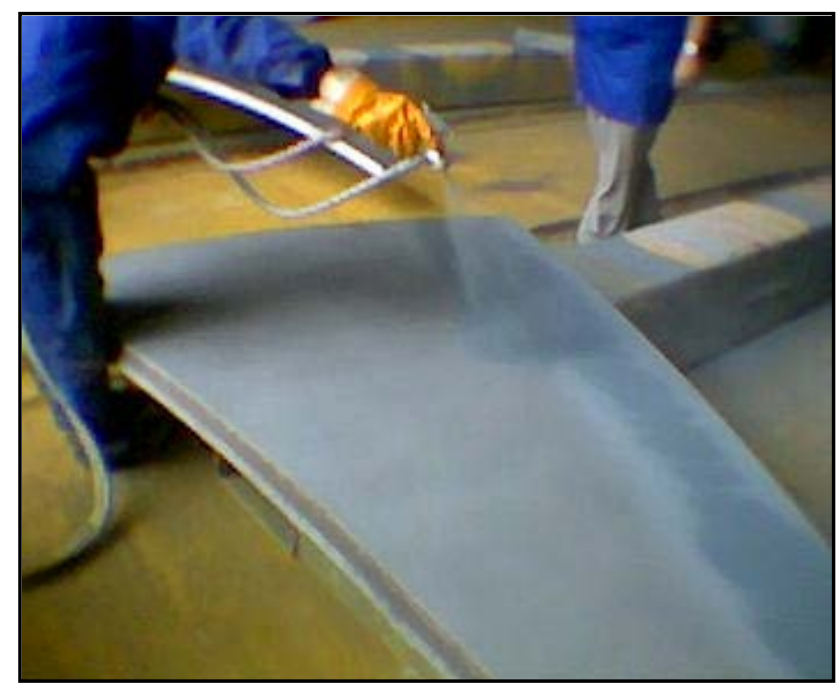

Figure 8. Body-of-proof (BP) painting with spray gun.

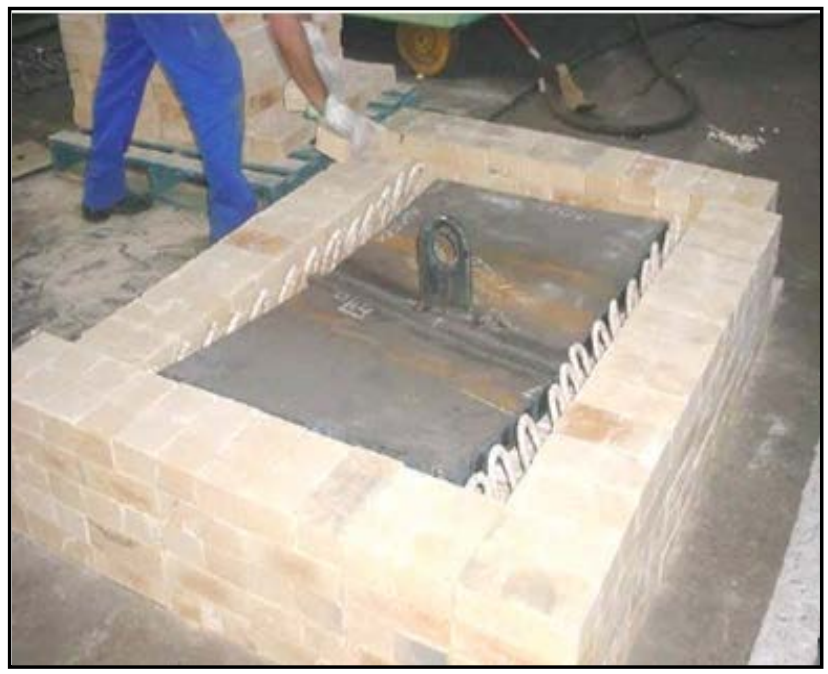

Figure 9. Body-of-proof (BP) under heat treatment. 
phosphate paint was applied to give a film with a minimum thickness of $100 \mu \mathrm{m}$ over the outside of the BP.

The application method used a conventional pistol with a mechanical stirrer and environmental conditions occurred based on the Petrobras standard N-0013 [11] and ABNT NBR 11003 [12].

The purpose of this test is to measure the mechanical tensile strength of a coating. The sample is subjected to increasing tensile stresses until the weakest path through the material fractures. The acceptance criterion for pull-off adhesion testing using the ASTM D-4541 [13] is that a value of at least $12 \mathrm{MPa}$ must be achieved. The results obtained for 13.6, 15.6, and 15.1 MPa are shown in Figure 11.

\section{Evaluation of Assembly Process with the Modules Painted with Ethyl Silicate Zinc Modified Paint (Shop Primer Paint)}

Through the application of the methodology presented with the qualification of the procedure, the paint scheme with modified shop primer paint has been implemented in the manufacture and assembly of liquefied petroleum gas storage spheres in oil and refinery.

The results were considered excellent compared to conventional scheme paint, providing the following improvements:

- elimination of blasting activity in the field;

- reduction in labour costs by approximately 2400 person hours;

- reduction of the amount of painting work done in a confined space;

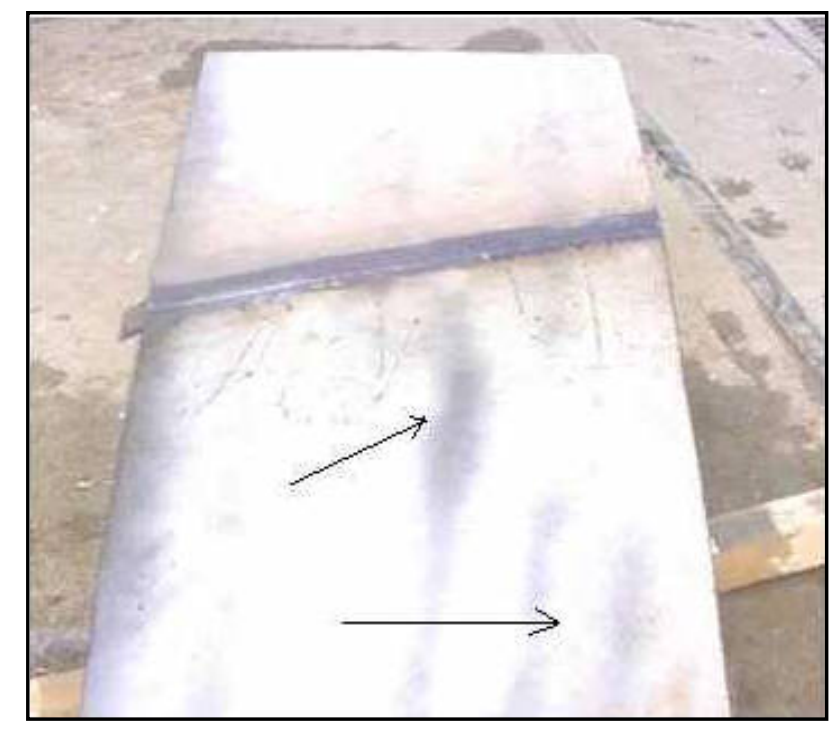

Figure 10. The BP presented dark spots after heat treatment.

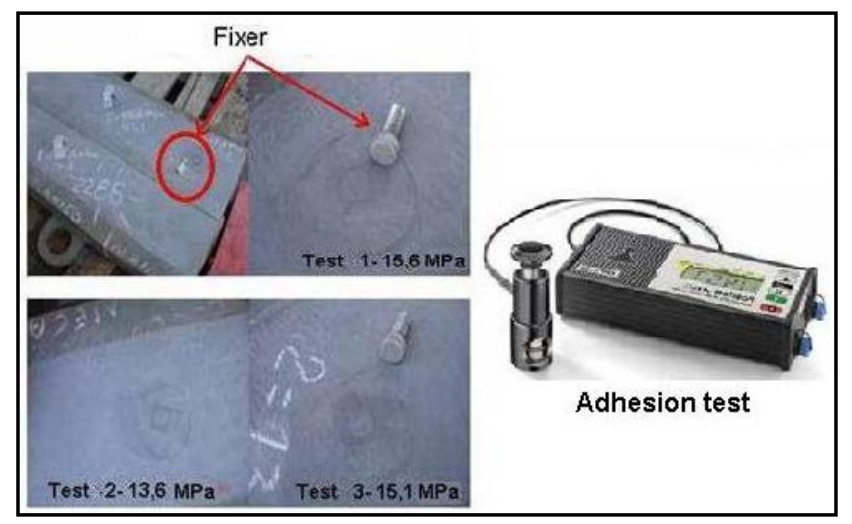

Figure 11. Following the adhesion test. 
- reduction of noise pollution and noise index;

- reduction of polluting agents in the field, where they are more difficult to control (whereas in the new scheme most of the modules are welded at the factory, where the highest level of control is possible);

- equality of the roughness profile for the application of paint because this was obtained in the factory under better technical and operational conditions than on the field;

- reduction of delivery time by at least 30 days.

\section{Conclusions}

Due to the need for refineries to expand the production of petroleum gas storage spheres, in a short time, the manufacture and assembly of storage spheres has become one of the main objectives of equipment manufacturers.

Through this challenge and based on the excellent test results, an alternative system that achieves this goal has been implemented, improving work safety and leading to higher productivity and better quality of the environment. These factors have resulted in clean conditions, providing a considerable reduction in unsafe conditions and waste generation.

\section{References}

[1] Terzi, R. and Mainier, F.B. (2008) Internal Corrosion Monitoring Offshore Platforms. Tecno-Lógica, Santa Cruz do Sul, 14-21 (in Portuguese).

[2] Roberge, P.R. (2000) Handbook of Corrosion Engineering. Vol. 1128. McGraw-Hill, New York.

[3] Gentil, V. (2011) Corrosion. 6th Edition, LTC Livros Técnicos e Científicos (Publisher), Rio de Janeiro (in Portuguese).

[4] Mansfeld, F. (2003) Electrochemical Methods of Corrosion Testing. ASM Handbook, 13, 446-462.

[5] Talbert, R. (2007) Paint Technology Handbook. CRC Press, Boca Raton. http://dx.doi.org/10.1201/9781420017786

[6] Petrobras Standard N-1375 (2007) Painting of Sphere and Cylinder for Liquefied Gas Storage Derived from Oil and Ammonia. Technical Standardisation Committee of Petrobras (in Portuguese).

[7] Petrobras Standard N-1841 (2007) Shop Ethyl-Silicate Zinc Primer. Technical Standardisation Committee of Petrobras (in Portuguese).

[8] Sadler, H. (2007) Sorting out Certifications for Welding Consumables. Welding Journal, 86, 42-45.

[9] Petrobras Standard CQEQ-064 (2007) Qualification of Procedure of Storage Sphere Painting of Liquefied Petroleum. Technical Standardisation Committee of Petrobras (in Portuguese).

[10] ISO 8501 (2000) Preparation of Steel Substrates before Application of Paints and Related Products.

[11] Petrobras Standard N-0013 G (2004) Technical Requirements for Painting Services, CONTEC, Technical Standardisation Committee of Petrobras (in Portuguese).

[12] ABNT NBR 11003 (1990) Determination of adherence. Brazilian Association of Technical Standards (in Portuguese).

[13] ASTM D 4541 (2000) Standard Test Method for Pull-Off Strength of Coatings Using Portable Adhesion Testers. 